\title{
Clinical and radiological factors associated with unfavorable outcome after intravenous thrombolysis in patients with mild ischemic stroke
}

Dae-Hyun Kim ${ }^{1,2^{*}}$, Deok-Soo Lee ${ }^{2}$, Hyun-Wook Nah ${ }^{1,2}$ and Jae-Kwan Cha ${ }^{1,2}$

\begin{abstract}
Background: A significant proportion of patients with mild ischemic stroke become disabled despite receiving intravenous thrombolytic therapy. The purpose of this study was to assess the clinical and radiological factors associated with unfavorable outcomes in patients with minor ischemic stroke that received intravenous recombinant tissue plasminogen activator (rt-PA) therapy.

Methods: We identified anterior circulation stroke patients with initial National Institutes of Health Stroke Scale (NIHSS) scores $\leq 5$ who received intravenous thrombolysis within $4.5 \mathrm{~h}$ of stroke onset and had pretreatment magnetic resonance (MR)/MR angiography using our prospective stroke database. We analyzed baseline characteristics, infarction patterns on diffusion-weighted imaging (DWI), and steno-occlusive lesions on MR angiography. Unfavorable outcome was defined as a modified Rankin Scale (mRS) score $\geq 2$ at 90 days. Logistic regression was used to determine independent predictors of unfavorable outcomes.

Results: Among 121 patients (85 men; mean age, $63.4 \pm 11.3$ years) included in this study, 46 (38\%) had unfavorable outcomes at 90 days and DWI lesion patterns showing infarction in the deep middle cerebral artery (MCA) territory involving the perforating artery area was observed in 47 (38.8\%) patients. On multivariable analysis, unfavorable outcomes at 90 days were associated with diabetes [odds ratio (OR), 3.41; 95\% confidence interval $(C I), 1.06-10.9 ; P=0.039)$, NIHSS score on admission $(\mathrm{OR}, 2.11 ; 95 \% \mathrm{Cl}, 1.35-3.30 ; P=0.001)$, and infarction in the deep MCA territory on DWI $(\mathrm{OR}, 4.19 ; 95 \% \mathrm{Cl}, 1.63-10.8 ; P=0.003)$. Lesions in the deep MCA territory was independently associated with early neurological deterioration $(P=0.032)$. The patients without deep MCA territory infarction had a higher prevalence of cardiac embolism $(P=0.009)$.
\end{abstract}

Conclusions: Higher NIHSS scores, diabetes, and deep MCA territory infarction may be useful for predicting unfavorable outcomes in patients with minor stroke treated with intravenous rt-PA therapy.

Keywords: Mild ischemic stroke, Recombinant tissue plasminogen activator, Diffusion-weighted imaging

\footnotetext{
* Correspondence: kdh6542@hanmail.net

${ }^{1}$ Busan-Ulsan Regional Cardiocerebrovascular Center, Dong-A University Hospital, Busan, Republic of Korea

2Department of Neurology, College of Medicine, Dong-A University, 1, 3-ga

Dongdaesin-dong, Seo-gu, Busan 602-715, Republic of Korea
}

(c) The Author(s). 2018 Open Access This article is distributed under the terms of the Creative Commons Attribution 4.0 International License (http://creativecommons.org/licenses/by/4.0/), which permits unrestricted use, distribution, and reproduction in any medium, provided you give appropriate credit to the original author(s) and the source, provide a link to the Creative Commons license, and indicate if changes were made. The Creative Commons Public Domain Dedication waiver (http://creativecommons.org/publicdomain/zero/1.0/) applies to the data made available in this article, unless otherwise stated. 


\section{Background}

More than half of all ischemic stroke patients exhibit a clinical syndrome with mild neurological deficit $[1,2]$. Intravenous thrombolysis with recombinant tissue plasminogen activator (rt-PA) within $4.5 \mathrm{~h}$ has been proven to be an effective treatment for acute ischemic stroke, but its benefits and risks in mild strokes are still unclear [3]. When patients with a mild stroke received intravenous thrombolytic therapy, approximately $30 \%$ of them had an unfavorable outcome [3-5]. Thus, it is of great importance to identify the patients at risk of unfavorable outcomes in the acute phase to prevent neurological deterioration and to predict outcomes in minor ischemic strokes treated with intravenous thrombolysis.

Magnetic resonance imaging (MRI) with diffusionweighted imaging (DWI) is superior to computed tomography (CT) for early detection of hyperacute and small ischemic lesions. Pretreatment DWI lesion patterns may be helpful in predicting clinical outcome in patients with acute ischemic stroke [6, 7]. Steno-occlusive lesions of the cerebral artery are associated with unfavorable outcomes in patients with minor strokes $[8,9]$. However, it is unclear whether the pretreatment lesions pattern on DWI and the presence of steno-occlusive lesions in relevant arteries can predict outcome following rt-PA thrombolysis in patients with minor stroke.

The aim of our study was to elucidate the clinical and pretreatment radiological factors associated with an unfavorable outcome after intravenous thrombolysis in patients with minor stroke.

\section{Methods}

We identified 682 consecutive patients in our prospectively collected institutional stroke database treated with intravenous rt-PA therapy within $4.5 \mathrm{~h}$ after symptom onset, independent of performance of emergent endovascular treatment between January 2010 and December 2016. During this period, MRI was systematically adopted at our center as the first-line imaging modality [DWI, fluidattenuated inversion recovery, gradient echo sequences, and time of flight magnetic resonance angiography (MRA)] in the absence of contraindications to MRI. Eligible patients were treated with intravenous rt-PA according to clinical guidelines. No upper or lower National Institutes of Health Stroke Scale (NIHSS) threshold was applied. Follow up MRI or CT were performed $24 \mathrm{~h}$ after intravenous rt-PA thrombolysis in all patients.

Patients were included in our study if they had an anterior circulation stroke with an initial NIHSS score of 1 to 5 and pretreatment MRI including DWI and MRA. We excluded patients who; (1) had a pre-stroke modified Rankin scale core $(\mathrm{mRS})>1$, (2) received subsequent endovascular treatment combined with intravenous thrombolysis, (3) had no definitive evidence of focal hyperintensities in clinically relevant areas on initial or follow up DWI, or (4) had no follow-up data.

Demographic, clinical and laboratory data were collected from the prospectively collected stroke registry. Baseline data included initial NIHSS scores and onsetto-rt-PA treatment times. Mild stroke was defined as a baseline NIHSS score 1-5 [5]. The etiologic stroke subtype was defined according to the Trial of Org 10,172 in Acute Stroke Treatment (TOAST) criteria [10].

This study was approved by the Institutional Review Board of Dong-A University Hospital.

\section{Imaging analysis}

Two investigators (D.-H. K and D.-S. L) who were blinded to the patients' clinical characteristics reviewed the pretreatment DWI and MRA images and follow up DWI at $24 \mathrm{~h}$ after intravenous thrombolysis. Discrepancies were resolved by consensus. DWI lesion pattern were classified as perforating artery infarcts (PAI), pial infarcts, border-zone infarcts, territorial infarcts and PAI plus additional infarcts outside the perforating artery territory, by modification of previous studies (Fig. 1) [11].

These findings were also divided into two different groups according to the presence of infarcts in the territory of the perforating arteries involving the internal capsule, corona radiata, and basal ganglia. Deep middle cerebral artery (MCA) infarction with or without infarctions outside the perforating artery territory were classified as Group A while the other 3 lesion patterns were classified as Group B.

Stenosis or occlusion of the arteries related to ischemia were determined via analysis of the initial MRA, which included the entire internal carotid artery, MCA (M1 proximal, M1 distal, and M2 segment), and anterior cerebral artery (ACA; A1 segment). Arterial occlusion was defined as a complete loss of distal flow signal. Moderate to severe arterial stenosis was defined as a $50 \%$ narrowing of the lumen and focal signal loss in the presence of a distal flow signal.

\section{Clinical outcomes}

Early neurological deterioration (END) was defined as an increase of 2 or more points in the NIHSS scores between hospital days 0 and 5 . Outcome was assessed using the mRS score at 3 months from stroke onset and was dichotomized into favorable (mRS $0-1$ ) and unfavorable (mRS 2-6). Symptomatic intracerebral hemorrhage was defined as blood at any site in the brain associated with clinical deterioration resulting in an NIHSS score increase of $\geq 4$ points [12].

\section{Statistical analysis}

The results are expressed as mean (standard deviation) or median (range), as appropriate, throughout the text 


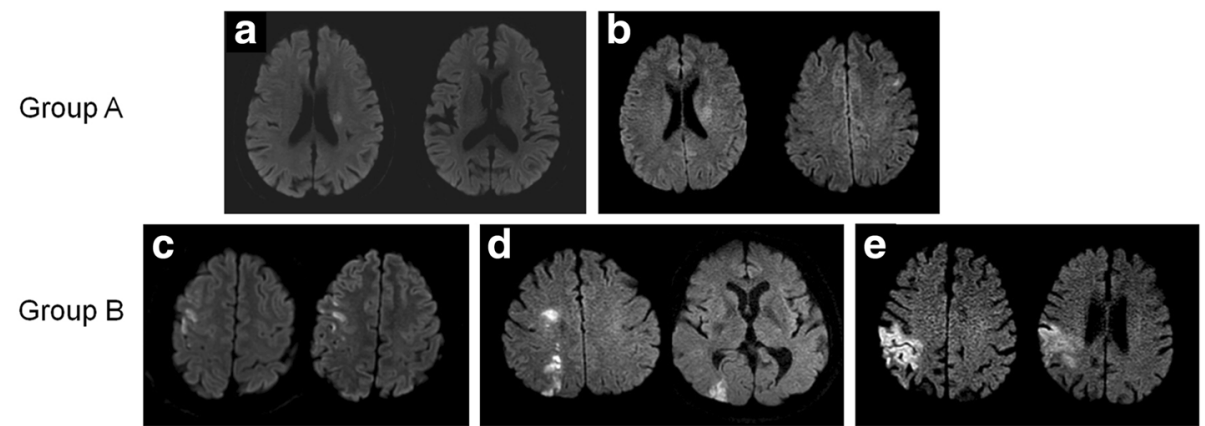

Fig. 1 Examples of the five different diffusion-weighted imaging patterns analyzed and the classification into two groups. Lesion patterns were classified as perforating artery infarcts (a), perforating artery infarcts with additional infarcts outside the perforating artery territory (b), pial infarcts (c), border-zone infarcts (d) and territorial infarcts (e)

and tables. The differences in patients' characteristics and their relation to 90 -day outcomes $(\mathrm{mRS} \leq 1$ vs. $\mathrm{mRS} \geq 2$ ) were analyzed. For dichotomous outcomes, the chi-squared or Fisher's exact test are reported where appropriate. For outcomes with continuous data, comparisons were performed using Student's t test or the MannWhitney $\mathrm{U}$ test, depending on the normality of data distribution. Multivariate logistic regression analysis was performed to determine factors that could be considered to be independent predictors of unfavorable outcome after intravenous rt-PA thrombolysis. Variables showing a value of $P<0.2$ in univariate analysis were included in the multivariate model. A probability value $<0.05$ was considered statistically significant.

\section{Results}

A total of 202 patients with baseline NIHSS $\leq 5$ were treated with intravenous thrombolysis. We excluded 42 patients with posterior circulation strokes, 18 patients without hyperintensity lesions on pretreatment and follow-up DWI, 5 patients who received endovascular treatment, 5 patients with an initial NIHSS of 0,5 patients with unavailable or insufficient quality DWI, 3 patients with mRS 2-6 prior to the stroke, and 3 patients without an mRS assessment at 3 months Finally, 121 patients (85 men and 36 women; mean age, 63.4 \pm 11.3 years) were included in the study (Fig. 2). The median baseline NIHSS score was 4 (interquartile range, 35). Among 121 patients, 46 (38\%) had unfavorable outcomes (mRS score 2-6) at 90 days. Symptomatic intracerebral hemorrhages were rare (1.7\%).

Table 1 presents the general characteristics and radiologic features of patients with and without unfavorable outcomes. In univariate analysis, diabetes $(P=0.007)$, non-cardiac embolism $(P=0.04)$, higher NIHSS scores $(P=0.003)$, and deep MCA territory infarction $(P<$ 0.001 ) were more frequently observed in patients with an unfavorable outcome. The onset-to-rt-PA time was $141.6 \pm 58$ and $145.6 \pm 67 \mathrm{~min}$ in the favorable and unfavorable groups, respectively, and did not differ significantly $(P=0.728)$. Visible arterial occlusion before rtPA was observed in $33 \%$ of patients. They were comprised of ICA occlusion $(N=8)$, M1 proximal occlusion $(N=10)$, M1 distal occlusion $(N=11), \mathrm{M} 2$ occlusion $(N$ $=9)$, and ACA occlusion $(N=2)$ on MRA. There was no difference in favorable outcome following intravenous thrombolysis between mild stroke patients with and without large artery occlusion.

After univariate analysis, hyperlipidemia $(P=0.058)$, age, sex, previous stroke, and steno-occlusive disease $(P$ $=0.181$ ) were also included in the multivariate logistic regression. Multivariate logistic regression analysis showed that diabetes [odds ratio (OR), 3.41; 95\% confidence interval (CI), 1.06-10.9; $P=0.039]$, higher NIHSS scores on admission (OR, 2.11; 95\% CI, 1.35-3.30; $P=$ 0.001 ), and infarction in the deep MCA territory (OR, 4.19; $95 \% \mathrm{CI}, 1.63-10.8 ; P=0.003$ ) were independently associated with unfavorable outcome (Table 2).

A DWI lesion pattern with infarction in the deep MCA territory (Group A) was observed in 47 (38.8\%) patients. Group A was independently associated with END $(P=0.032)$ and moderate to severe $(>50 \%)$ stenosis in the relevant artery $(P=0.019)$. The patients without lesions in the deep MCA territory (Group B) had a higher prevalence of cardiac embolism $(P=0.009)$ (Additional file 1: Table S1, Fig. 3).

\section{Discussion}

This study showed that a large proportion (38\%) of patients receiving intravenous thrombolysis for minor strokes will have an unfavorable outcome at 90 days. Symptomatic intracerebral hemorrhages were rare. Baseline NIHSS score, diabetes mellitus, and deep MCA infarction with lesions in the perforating artery territory were independently associated with unfavorable outcomes.

According to recent reports, age $[5,13]$, diabetes mellitus $[5,8,9,14]$, previous stroke [14], intra-or extracranial vascular occlusive lesions $[8,9]$ and NIHSS score $[5,15]$ 


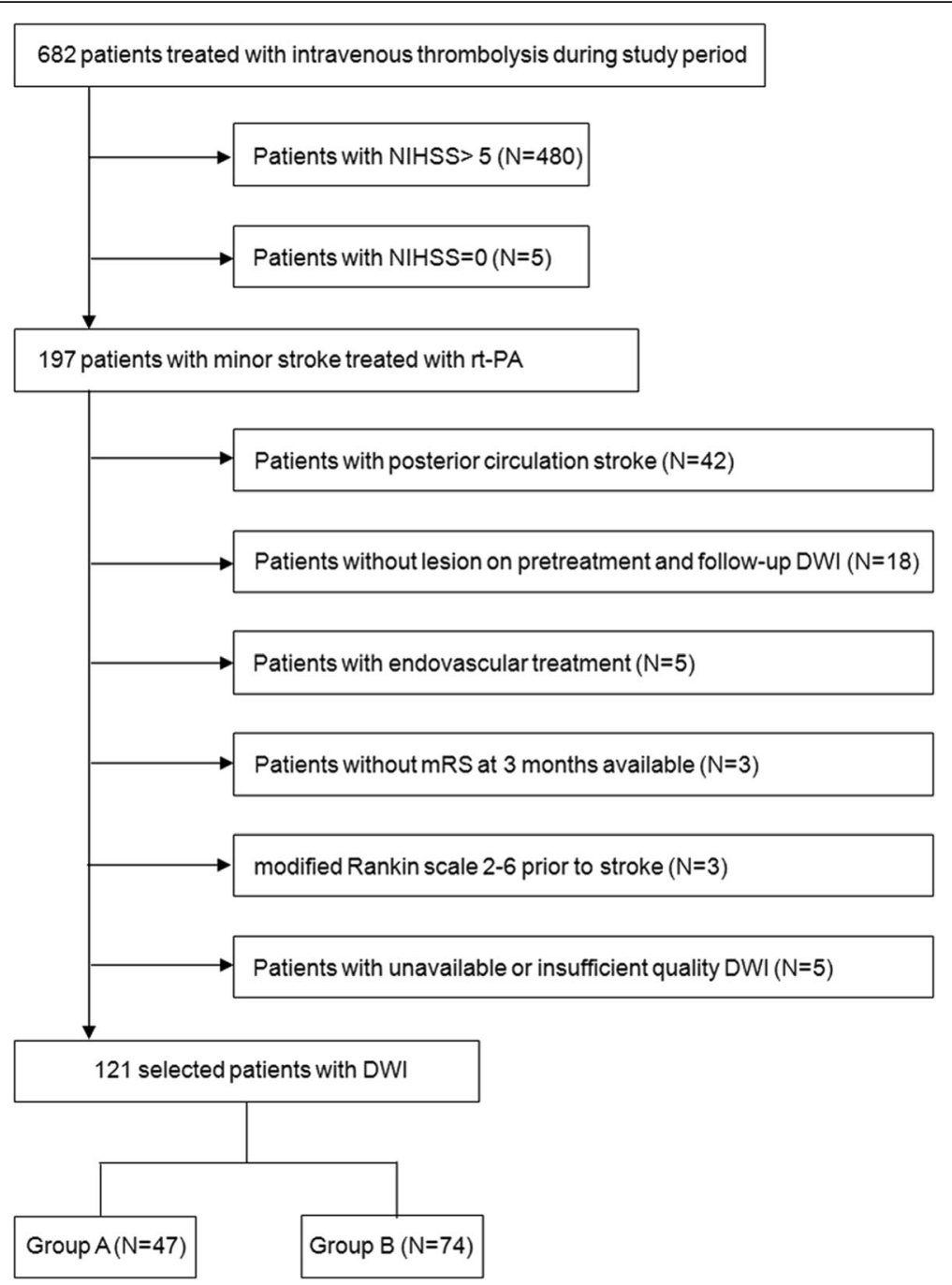

Fig. 2 Schematic description of the patient selection process

were associated with unfavorable outcomes in patients with minor strokes. However, these studies explored the factors associated with disability at 90 days in mild stroke patients not treated with thrombolytic therapy.

It remains to be determined whether the presence of steno-occlusive lesions leads to unfavorable outcomes in mild stroke patients following intravenous rt-PA treatment. As opposed to previous reports on nonthrombolytic therapy [8,9], we did not find an association between large artery occlusion and unfavorable outcome following intravenous rt-PA therapy. This is in line with previous reports that also found no differences in outcome following intravenous thrombolysis between mild stroke patients with and without large artery occlusion $[16,17]$. Mild stroke patients tend to have more distal artery occlusion, lower thrombus burden, and higher recanalization rates or have central occlusions with good collaterals [18-20]. This might be the reason why even patients with large artery occlusion do not have different outcome following intravenous rt-PA therapy compared to those without.

Previous studies have shown that acute lesion patterns may predict prognosis or stroke recurrence after ischemic stroke [11, 21] but it remains unclear whether such imaging factors are related to patient outcome after intravenous thrombolysis in mild ischemic stroke. Patients with perforating artery infarcts in the basal ganglia and corona radiata were more likely to have unfavorable outcomes in this study. These finding may be explained by several hypothesis.

First, Strambo et al. [15] reported that among all NIHSS items, only impairment of motor items is significantly associated with poor outcome in mild stroke. Since the deep MCA territory is crossed by the corticospinal tract [22] and is prone to damage by poor collateral flow [23], this area may be susceptible to motor 
Table 1 Characteristics of the study population according to outcomes at 3 months

\begin{tabular}{|c|c|c|c|c|}
\hline & All patients $(n=121)$ & $\mathrm{mRS}=0-1 \quad(n=75)$ & $\mathrm{mRS}=2-6(n=46)$ & $P$-value \\
\hline Age (mean $\pm S D)$ & $63.4 \pm 11.3$ & $63.2 \pm 10.5$ & $63.8 \pm 12.6$ & 0.769 \\
\hline Sex, $n(\%)$ & & & & 0.490 \\
\hline Men & $85(70.2)$ & $51(68)$ & $34(73.9)$ & \\
\hline Female & $36(29.8)$ & $24(32)$ & $12(26.1)$ & \\
\hline \multicolumn{5}{|l|}{ Risk factor, n(\%) } \\
\hline Hypertension & $61(50.8)$ & $36(48.6)$ & $25(54.3)$ & 0.544 \\
\hline Diabetes & $33(27.3)$ & 14(18.7) & 19(41.3) & 0.007 \\
\hline Hyperlipidemia & $17(14)$ & $7(9.3)$ & $10(21.7)$ & 0.057 \\
\hline Atrial fibrillation & $22(18.2)$ & $16(21.3)$ & $6(13)$ & 0.251 \\
\hline Current smoking & $31(25.6)$ & $20(26.7)$ & $11(23.9)$ & 0.736 \\
\hline Previous coronary artery disease & 14(11.6) & 10(13.3) & $4(8.7)$ & 0.564 \\
\hline Previous stroke or TIA & $11(9.1)$ & $6(8.0)$ & $5(10.9)$ & 0.746 \\
\hline NIHSS on admission, (med, IQR) & $4[3-5]$ & $4[2-4]$ & $4[3-5]$ & 0.003 \\
\hline (mean $\pm S D)$ & $3.6 \pm 1.2$ & $3.4 \pm 1.2$ & $4.0 \pm 1.1$ & 0.004 \\
\hline Onset to rt-PA time, (mean \pm SD) & $143.1 \pm 61.4$ & $141.6 \pm 57.9$ & $145.6 \pm 67.2$ & 0.728 \\
\hline Blood glucose on admission, mg/dL & $143.4 \pm 52.6$ & $134.7 \pm 44.9$ & $157.6 \pm 61.0$ & 0.019 \\
\hline Initial systolic blood pressure, mmHg & $145.6 \pm 26.3$ & $145.4 \pm 27.9$ & $145.8 \pm 23.5$ & 0.924 \\
\hline Etiologic stroke subtypes, $n(\%)$ & & & & 0.302 \\
\hline Small vessel disease & $25(20.7)$ & 13(17.3) & $12(26.1)$ & 0.248 \\
\hline Large artery disease & $36(29.8)$ & $22(29.3)$ & 14(30.4) & 0.298 \\
\hline Cardiac embolism & $34(28.1)$ & $26(34.7)$ & $8(17.4)$ & 0.040 \\
\hline Undetermined etiology & $26(21.5)$ & 14(18.7) & $12(26.1)$ & 0.335 \\
\hline Lesions on pretreatment DWI, n(\%) & & & & 0.317 \\
\hline Acute infarcts $(+)$ & 110(91.7) & $67(89.3)$ & 43(95.6) & \\
\hline No lesions & $10(8.3)$ & $8(10.7)$ & $2(4.4)$ & \\
\hline \multicolumn{5}{|l|}{ Lesion patterns on DWI, n(\%) } \\
\hline Perforating artery infarcts & $27(22.3)$ & $12(16)$ & 15(32.6) & 0.033 \\
\hline Pial infarcts & $51(42.1)$ & $40(53.3)$ & $11(23.9)$ & 0.001 \\
\hline Borderzone infarcts & $6(5)$ & $5(6.7)$ & $1(2.2)$ & 0.406 \\
\hline Territorial infarcts & $17(14)$ & 10(13.3) & $7(15.2)$ & 0.772 \\
\hline Perforating artery infarcts plus & $20(16.5)$ & $8(10.7)$ & $12(26.1)$ & 0.027 \\
\hline Deep MCA infarcts (PAI + PAI plus) & $47(38.8)$ & $20(26.7)$ & $27(58.7)$ & $<0.001$ \\
\hline Angiographic findings of relevant artery, $n(\%)$ & & & & 0.383 \\
\hline No stenosis or occlusion & $62(51.2)$ & $42(56)$ & $20(43.5)$ & \\
\hline Stenosis (> 50\%) & 19(15.7) & 10(13.3) & $9(19.6)$ & \\
\hline Occlusion & $40(33.1)$ & 23(30.7) & $17(37)$ & \\
\hline Steno-occlusive disease, $n(\%)$ & $59(48.8)$ & $33(44)$ & $26(56.5)$ & 0.181 \\
\hline END, $n(\%)$ & 14(11.6) & $3(4)$ & $11(23.9)$ & 0.002 \\
\hline Symptomatic ICH, $n(\%)$ & $2(1.7)$ & $1(1.3)$ & $1(2.2)$ & 1.000 \\
\hline
\end{tabular}

TIA transient ischemic attack, DWI diffusion-weighted imaging, MCA middle cerebral artery, PAl perforating artery infarction, END early neurological deterioration, $\mathrm{ICH}$ intracranial hemorrhage

deficits, regardless of rt-PA thrombolysis. In some reports, patients with deep white matter or basal ganglia infarction have suffered from bad outcomes after thrombolysis or endovascular therapy [7, 22, 23]. Thus, even small lesions in this area could be critical to the outcome of mild ischemic stroke.

Second, END is an important factor associated with worse clinical outcome in minor strokes [9]. Several 
Table 2 Multivariable analysis for unfavorable outcome at 90 days

\begin{tabular}{|c|c|c|c|}
\hline & Unfavorable c & & \\
\hline & Adjusted OR & $95 \% \mathrm{Cl}$ & $P$-value \\
\hline Age - per 1 year & 1.01 & $0.96-1.05$ & 0.914 \\
\hline Men & 1.95 & $0.69-5.48$ & 0.205 \\
\hline Diabetes & 3.41 & $1.06-10.9$ & 0.039 \\
\hline Hyperlipidemia & 2.92 & $0.81-10.5$ & 0.102 \\
\hline Previous stroke or TIA & 1.29 & $0.29-5.65$ & 0.755 \\
\hline NIHSS on admission & 2.11 & $1.35-3.30$ & 0.001 \\
\hline Initial serum glucose & 1.01 & $0.99-1.01$ & 0.306 \\
\hline Cardiac embolism & 0.48 & $0.16-1.46$ & 0.195 \\
\hline Presence of deep MCA infarction & 4.19 & $1.63-10.8$ & 0.003 \\
\hline Steno-occlusive disease & 1.6 & $0.63-3.72$ & 0.351 \\
\hline
\end{tabular}

Adjusted by age, sex and previous stroke

patients with infarcts in the perforator territory have END (29.1\%) [13] and this rate was similar to that in patients with small vessel disease that received intravenous rt-PA therapy (33\%) [24]. In our study, ENDs were more prevalent in Group A patients and were associated with unfavorable outcomes. These results may have important clinical implications. Previous study has shown that rtPA use in acute lacunar stroke does not affect END [24]. Thus, special attention should be paid to patients with infarcts in the perforating territory, even when they show mild neurological deficits at the time of presentation and after rt-PA therapy.

Lastly, Group B was more likely to have cardiac embolism. This can be explained by a previous report that demonstrated a mild stroke caused by cardiac embolism could reveal small cortical lesions and lead to a high rate of neurological improvement [15]. However, Hao et al. [25] reported that in mild stroke, cardiac embolism was a predictor of death or disability at 3 months and that patients with small vessel occlusion had better outcomes. That study enrolled mild stroke patients within 30 days after stroke onset. There is a possibility that non-cardiac embolism patients with early worsening or early recurrence were excluded from that study, whereas we included patients treated with rt-PA therapy within $4.5 \mathrm{~h}$. Further studies are needed to confirm whether cardiac embolism can be a protective factor in ischemic stroke with mild symptoms.

A significant strength of our study is that all patients underwent pretreatment MRI. DWI has the advantage of capturing small infarctions and detection of early ischemic changes in patients with acute mild ischemic stroke, unlike CT. Few studies on whether pretreatment DWI lesions pattern and arterial occlusion on MRA can predict outcome in mild stroke are available $[21,26]$. To the best of our knowledge, this is the largest study to investigate the DWI findings in patients with mild stroke treated with rt-PA therapy.

The most notable limitation of our study is the uncontrolled, non-randomized design since this was a single hospital-based study. Limitations to using clinical

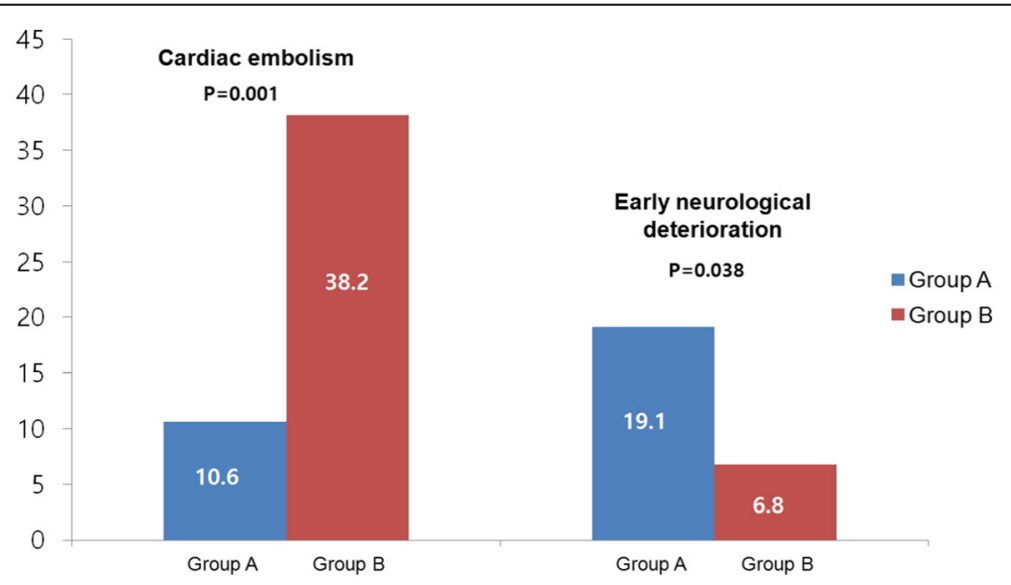

Fig. 3 Comparison of the general characteristics of group (a) and (b) 
registry data may include the introduction of bias in patient selection including the imbalance of sex ratio in this study. Thus, generalizing the results of this study to other patient populations may be challenging.

\section{Conclusions}

We found that in spite of intravenous rt-PA treatment, approximately $40 \%$ of anterior circulation stroke patients with minor symptom had unfavorable outcomes at 3 months. Higher NIHSS scores, diabetes and deep MCA infarction with involvement of the perforating artery territory were associated with unfavorable outcomes after rtPA therapy in patients with minor stroke. Brain MRIDWI patterns assessed in the acute phase of mild stroke are useful to predict those patients at high risk of unfavorable outcome following rt-PA therapy.

\section{Additional file}

Additional file 1: Table S1. Univariate and multivariable analysis of factors associated with Group A lesion pattern in diffusion-weighted imaging. (DOCX $18 \mathrm{~kb})$

\section{Abbreviations}

ACA: Anterior cerebral artery; CT: Computed tomography; DWI: Diffusionweighted imaging; END: Early neurological deterioration; MCA: Middle cerebral artery; MRA: Magnetic resonance angiography; MRI: Magnetic resonance imaging: mRS: modified Rankin scale core; NIHSS: National Institutes of Health Stroke Scale; PAI: Perforating artery infarcts; rtPA: recombinant tissue plasminogen activator; TOAST: Trial of Org 10,172 in Acute Stroke Treatment

\section{Acknowledgements}

Not applicable

\section{Funding}

This work was supported by the Dong-A University research fund.

\section{Availability of data and materials}

The datasets generated and/or analysed during this study are available from the corresponding author upon reasonable request.

\section{Authors' contributions}

DHK: conception and design, drafting the manuscript and revising it critically for important intellectual content. DSL: conception and design, acquisition of data and drafting the manuscript. HWN: acquisition of data, data analysis and drafting manuscript. JKC: conception and design, data collection and data interpretation. All authors have read and approved the final manuscript.

\section{Ethics approval and consent to participate}

Institutional Review Board of Dong-A University Hospital approved a request to waive of informed consent because it is not practicable to obtain consent from large numbers of patients for a retrospective chart review study, generally it also will not be appropriate to attempt to contact those patients to tell them about the study retrospectively. This study was approved by the Institutional Review Board of Dong-A University Hospital.

\section{Consent for publication}

Consent provided upon request.

\section{Competing interests}

The authors declare that they have no competing interests.

\section{Publisher's Note}

Springer Nature remains neutral with regard to jurisdictional claims in published maps and institutional affiliations.

Received: 9 November 2017 Accepted: 2 March 2018

Published online: 15 March 2018

\section{References}

1. Reeves M, Khoury J, Alwell K, Moomaw C, Flaherty M, Woo D, Khatri P, Adeoye O, Ferioli S, Kissela B, Kleindorfer D. Distribution of national institutes of health stroke scale in the Cincinnati/northern Kentucky stroke study. Stroke. 2013:44:3211-3.

2. Kim BJ, Park JM, Kang K, Lee SJ, Ko Y, Kim JG, Cha JK, Kim DH, Nah HW, Han MK, Park TH, Park SS, Lee KB, Lee J, Hong KS, Cho YJ, Lee BC, Yu KH, Oh MS, Kim DE, Ryu WS, Cho KH, Kim JT, Choi JC, Kim WJ, Shin DI, Yeo MJ, Sohn SI, Hong JH, Lee JS, Yoon BW, Bae HJ. Case characteristics, hyperacute treatment, and outcome information from the clinical research center for stroke-fifth division registry in South Korea. J Stroke. 2015;17:38-53.

3. Yu AY, Hill MD, Coutts SB. Should minor stroke patients be thrombolyzed? A focused review and future directions. Int J Stroke. 2015;10:292-7.

4. Emberson J, Lees KR, Lyden P, Blackwell L, Albers G, Bluhmki E, Brott T, Cohen G, Davis S, Donnan G, Grotta J, Howard G, Kaste M, Koga M, von Kummer R, Lansberg M, Lindley Rl, Murray G, Olivot JM, Parsons M, Tilley B, Toni D, Toyoda K, Wahlgren N, Wardlaw J, Whiteley W, del Zoppo GJ, Baigent C, Sandercock P, Hacke W. Effect of treatment delay, age, and stroke severity on the effects of intravenous thrombolysis with alteplase for acute ischaemic stroke: a meta-analysis of individual patient data from randomised trials. Lancet. 2014;384:1929-35.

5. Romano JG, Smith EE, Liang L, Gardener H, Camp S, Shuey L, Cook A, Campo-Bustillo I, Khatri P, Bhatt DL, Fonarow GC, Sacco RL, Schwamm LH. Outcomes in mild acute ischemic stroke treated with intravenous thrombolysis: a retrospective analysis of the get with the guidelines-stroke registry. JAMA Neurol. 2015;72:423-31.

6. Bang OY, Lee PH, Heo KG, Joo US, Yoon SR, Kim SY. Specific DWI lesion patterns predict prognosis after acute ischaemic stroke within the MCA territory. J Neurol Neurosurg Psychiatry. 2005;76:1222-8.

7. Liu D, Scalzo F, Starkman S, Rao NM, Hinman JD, Kim D, Ali LK, Saver JL, Noorian AR, Ng K, Liang C, Sheth SA, Yoo B, Liu X, Liebeskind DS. DWI lesion patterns predict outcome in stroke patients with thrombolysis. Cerebrovasc Dis. 2015:40:279-85.

8. Sato S, Uehara T, Ohara T, Suzuki R, Toyoda K, Minematsu K. Factors associated with unfavorable outcome in minor ischemic stroke. Neurology. 2014;83:174-81.

9. Coutts SB, Modi J, Patel SK, Aram H, Demchuk AM, Goyal M, Hill MD. What causes disability after transient ischemic attack and minor stroke?: results from the $C T$ and MRI in the triage of TIA and minor cerebrovascular events to identify high risk patients (CATCH) study. Stroke. 2012;43:3018-22.

10. Adams HP Jr, Bendixen BH, Kappelle LJ, Biller J, Love BB, Gordon DL, Marsh EE 3rd. Classification of subtype of acute ischemic stroke. Definitions for use in a multicenter clinical trial. TOAST trial of org 10172 in acute stroke treatment. Stroke. 1993;24:35-41.

11. Lee DK, Kim JS, Kwon SU, Yoo SH, Kang DW. Lesion patterns and stroke mechanism in atherosclerotic middle cerebral artery disease: early diffusionweighted imaging study. Stroke. 2005;36:2583-8.

12. Hacke W, Kaste M, Fieschi C, von Kummer R, Davalos A, Meier D, Larrue V, Bluhmki E, Davis S, Donnan G, Schneider D, Diez-Tejedor E, Trouillas P. Randomised double-blind placebo-controlled trial of thrombolytic therapy with intravenous alteplase in acute ischaemic stroke (ECASS II). Second EuropeanAustralasian acute stroke study investigators. Lancet. 1998:352:1245-51.

13. Yamamoto N, Terasawa Y, Satomi J, Sakai W, Harada M, Izumi Y, Nagahiro S, Kaji R. Predictors of neurologic deterioration in patients with small-vessel occlusion and infarcts in the territory of perforating arteries. J Stroke Cerebrovasc Dis. 2014;23:2151-5.

14. Strbian D, Piironen K, Meretoja A, Sairanen T, Putaala J, Tiainen M, Artto V, Rantanen K, Happola O, Kaste M, Lindsberg PJ. Intravenous thrombolysis for acute ischemic stroke patients presenting with mild symptoms. Int J Stroke. 2013:8:293-9.

15. Strambo D, Zambon AA, Roveri L, Giacalone G, Di Maggio G, PeruzzottiJametti L, La Gioia S, Galantucci S, Comi G, Sessa M. Defining minor symptoms in acute ischemic stroke. Cerebrovasc Dis. 2015:39:209-15.

16. Zhu W, Churilov L, Campbell BC, Lin M, Liu X, Davis SM, Yan B. Does large vessel occlusion affect clinical outcome in stroke with mild neurologic deficits after intravenous thrombolysis? J Stroke Cerebrovasc Dis. 2014;23:2888-93. 
17. Kohrmann M, Nowe T, Huttner HB, Engelhorn T, Struffert T, Kollmar R, Saake M, Doerfler A, Schwab S, Schellinger PD. Safety and outcome after thrombolysis in stroke patients with mild symptoms. Cerebrovasc Dis. 2009;27:160-6.

18. Legrand L, Naggara O, Turc G, Mellerio C, Roca P, Calvet D, Labeyrie MA, Baron JC, Mas JL, Meder JF, Touze E, Oppenheim C. Clot burden score on admission T2*-MRI predicts recanalization in acute stroke. Stroke. 2013;44:1878-84.

19. Saqqur M, Uchino K, Demchuk AM, Molina CA, Garami Z, Calleja S, Akhtar N, Orouk FO, Salam A, Shuaib A, Alexandrov AV. Site of arterial occlusion identified by transcranial doppler predicts the response to intravenous thrombolysis for stroke. Stroke. 2007;38:948-54.

20. Strbian D, Ringleb P, Michel P, Breuer L, Ollikainen J, Murao K, Seiffge DJ, Jung S, Obach V, Weder B, Eskandari A, Gensicke H, Chamorro A, Mattle HP, Engelter S, Leys D, Numminen H, Kohrmann M, Hacke W, Tatlisumak T. Ultra-early intravenous stroke thrombolysis: do all patients benefit similarly? Stroke. 2013:44:2913-6.

21. Roquer J, Rodriguez-Campello A, Cuadrado-Godia E, Vivanco-Hidalgo RM, Jimenez-Conde J, Perich X, Ois A. Acute brain MRI-DWI patterns and stroke recurrence after mild-moderate stroke. J Neurol. 2010;257:947-53.

22. Rosso C, Colliot O, Valabregue R, Crozier S, Dormont D, Lehericy S, Samson Y. Tissue at risk in the deep middle cerebral artery territory is critical to stroke outcome. Neuroradiology. 2011;53:763-71.

23. Kawano H, Hirano T, Inatomi Y, Terasaki T, Yonehara T, Uchino M. Presence of deep white matter lesions on diffusion-weighted imaging is a negative predictor of early dramatic improvement after intravenous tissue plasminogen activator thrombolysis. Cerebrovasc Dis. 2010;30:230-6.

24. Hwang YH, Seo JG, Lee HW, Park SP, Suh CK. Early neurological deterioration following intravenous recombinant tissue plasminogen activator therapy in patients with acute lacunar stroke. Cerebrovasc Dis. 2008;26:355-9.

25. Hao Z, Liu M, Wang D, Wu B, Tao W, Chang X. Etiologic subtype predicts outcome in mild stroke: prospective data from a hospital stroke registry. BMC Neurol. 2013;13:154.

26. Desilles JP, Cho TH, Hermier M, Mechtouff-Cimarelli L, Derex L, Nighoghossian N. Magnetic resonance imaging-guided thrombolysis in minor stroke. Int J Stroke. 2011;6:178.

\section{Submit your next manuscript to BioMed Central and we will help you at every step:}

- We accept pre-submission inquiries

- Our selector tool helps you to find the most relevant journal

- We provide round the clock customer support

- Convenient online submission

- Thorough peer review

- Inclusion in PubMed and all major indexing services

- Maximum visibility for your research

Submit your manuscript at www.biomedcentral.com/submit

) Biomed Central 